\title{
OS PALAVRÕES NO PORTUGUÊS BAIANO: UMA ANÁLISE SOCIOLINGUÍSTICA COM BASE EM DOIS FILMES ${ }^{1}$
}

\section{CURSE WORDS IN THE PORTUGUESE OF BAHIA: A SOCIOLINGUISTIC ANALYSIS BASED ON TWO MOVIES}

\author{
Josane Moreira de Oliveira² \\ Universidade Estadual de Feira de Santana (UEFS) \\ Universidade Federal da Bahia (UFBA)
}

Resumo: Neste artigo, apresenta-se uma análise sociolinguística dos chamados 'palavrões' no português falado em Salvador - Bahia. Os dados foram recolhidos de dois filmes: Cidade Baixa e Ó Paí, Ó. O primeiro, de 2005, foi dirigido por Sérgio Machado; o segundo, de 2007, foi dirigido por Monique Gardenberg. Ambos os filmes retratam histórias que se passam na capital baiana e fornecem cenas do cotidiano que propiciam contextos de ocorrência de palavras e expressões consideradas de 'baixo calão'. Os dados foram levantados e analisados com o objetivo de fornecer uma análise que elenca os elementos linguísticos utilizados para expressar raiva, críticas e ofensas, considerando o seu sentido original, o sentido adquirido contextualmente e a possível relação com algumas variáveis linguísticas e sociais.

Palavras-Chave: Palavrões; Português baiano; Sociolinguística; Filmes.

1 Artigo dedicado ao Prof. Salah Mejri, da Université de Paris XIII, que, após longas conversas tentando encontrar um ponto em comum entre a minha área de pesquisa - a sociolinguística - e a sua - a fraseologia -, me convenceu a enveredar pelo estudo desse tema, tão novo, tão pouco investigado e, ao mesmo tempo, tão instigante.

2 Universidade Estadual de Feira de Santana - UEFS - Departamento de Letras e Artes. Feira de Santana - Bahia. E-mail: josanemoreira@hotmail.com. 
Abstract: In this article, we present a sociolinguistic analysis of so-called 'curse words' in Portuguese spoken in Salvador - Bahia. The data were collected from two movies: Cidade Baixa and Ó Paí, Ó. The former, released in 2005, was directed by Sérgio Machado; the latter, released in 2007, was directed by Monique Gardenberg. Both films recount stories that take place in Salvador, the capital of Bahia, and present scenes of daily life that provide contexts for the occurrence of words and expressions considered as 'low slang'. The data were collected and studied in order to provide an analysis that identifies specific linguistic elements used to express anger, criticism and offenses. We consider original meaning, contextually determined meaning and possible relation with some linguistic and social variables.

Keywords: Curse words; Portuguese of Bahia; Sociolinguistics; Movies.

\section{INTRODUÇÃO}

Estudar os 'palavrões' em qualquer língua que seja não é uma tarefa fácil. Primeiramente, é difícil justificar a relevância desse tipo de investigação. Em segundo lugar, é difícil coletar dados empíricos para uma pesquisa sobre esse tema, já que os 'palavrões' são emitidos em situações cotidianas que envolvem a expressão da carga emotiva do falante e que não costumam ocorrer durante as gravações normalmente feitas para a coleta de dados vernaculares, que subsidiam pesquisas linguísticas baseadas no uso.

Sabe-se, no entanto, que os 'palavrões' existem e são bastante utilizados em toda e qualquer língua e que despertam a curiosidade de aprendizes de uma língua estrangeira, por exemplo. No caso de uma língua estrangeira, o seu conhecimento é importante não só para o entendimento de piadas e anedotas como também para auto-proteção em situações cotidianas e para a consciência do uso de certos termos e expressões em contextos específicos.

No caso de língua materna, o conhecimento dos 'palavrões' faz parte da competência sócio-comunicativa dos falantes, que os aprendem ao longo do processo natural de aquisição da linguagem e das nuances linguísticas que caracterizam o processo comunicativo humano.

$\mathrm{Na}$ área da Linguística Cognitiva e da Lexicologia, há estudos que tangenciam o tema, ao abordarem os significados e a polissemia de certas palavras ou expressões, mas análises que investiguem o uso de 'palavrões' em comunidades linguísticas e sua relação com a contraparte social e cultural são raros ou inexistentes.

Considerando, pois, a relação intrínseca entre língua, cultura e sociedade, estudam-se neste texto os 'palavrões' no português baiano, tema muito pouco explorado nas pesquisas linguísticas empíricas pela dificuldade de registro desses enunciados. Os dados foram coletados de dois filmes - Cidade Baixa e Ó 
Paí, Ó - que ilustram o falar soteropolitano. Optou-se por essa fonte de dados por ser difícil a coleta desse tipo de dado em entrevistas tradicionais. Procedeuse a uma análise sociolinguística dos dados encontrados com o objetivo de descrever esses 'palavrões' e de contribuir para a caracterização do português falado em Salvador-BA.

Inicialmente, apresenta-se a conceituação dos 'palavrões', na seção 1. Na seção 2, de forma resumida, faz-se uma sinopse dos filmes que forneceram os dados da pesquisa com a justificativa para a escolha dos mesmos. Na seção 3, expõe-se a metodologia utilizada na coleta e no tratamento dos dados. Finalmente, na seção 4, procede-se à análise e à interpretação dos resultados. A seguir, sintetizam-se as conclusões desta investigação e listam-se as referências bibliográficas consultadas.

\section{OS 'PALAVRÕES'}

Segundo Ferreira (1986), 'palavrão' significa "palavra obscena ou grosseira" (primeira acepção do termo apresentada pelo autor). Houaiss (2001) define 'palavrão' como "palavra grosseira e/ou obscena" (terceira acepção apresentada pelo autor). Já Aulete (2007) traz uma única definição para o termo, "palavra que é considerada ofensiva, de mau gosto, cujo uso é considerado falta de educação". Os três autores consultados apresentam o termo 'palavrada' como sinônimo de 'palavrão'.

De acordo com a Wikipédia,

Uma palavra de baixo calão [...], popularmente conhecida como palavrão, é um vocábulo que pertence à categoria de gíria e, dentro desta, apresenta cunho chulo, impróprio, ofensivo, rude, obsceno, agressivo ou imoral sob o ponto de vista de algumas religiões, ou estilos de vida. [...] palavrões são formas inadequadas na norma culta da língua portuguesa e geralmente usados de forma popular e coloquial, exceto por licença poética. (WIKIPÉDIA, online)

Pelas definições constantes nos dicionários pesquisados, trata-se de algo considerado negativo, julgado como 'grosseiro', 'obsceno', 'ofensivo', de 'mau gosto', 'impróprio', 'rude', 'agressivo', 'imoral' e 'inadequado'. Envolvendo, pois, um juízo de valor social (às vezes também religioso), um 'palavrão' definido também como 'palavra de (baixo) calão' - é assim considerado a depender, pois, da subjetividade tanto do falante como do ouvinte num contexto discursivo e social específico. Isso significa que uma mesma expressão 
linguística, a depender da situação e do julgamento do falante e/ou do ouvinte, pode ou não ser um 'palavrão'.

Neste trabalho, entende-se por 'palavrões' os termos ou expressões que se utilizam em determinadas situações para expressar raiva, ódio, revolta, crítica, ofensa etc. Ou seja, são elementos linguísticos contextualmente produzidos com alta carga emocional do falante, que tem a intenção clara de exprimir esses sentimentos ou atitudes. Ao emitir um 'palavrão', o falante está emitindo um 'xingamento', que pode ser consciente ou impensado, fato que existe em todas as línguas humanas, já que é através da língua que o homem expressa também seus sentimentos. Para xingar, o falante se vale de palavras e expressões já existentes no seu repertório linguístico, imprimindo-lhes carga emotiva, seja por metáforas, por uma entonação diferente, por analogias ou extensões de significado, exprimindo ao máximo um sentimento ou uma atitude específicos e momentâneos, sejam bons ou ruins, indizíveis de outra forma naquela situação específica. A esse respeito, é muito interessante o que diz Pinker (2005):

Mais do que qualquer outra forma de linguagem, xingar recruta nossas faculdades de expressão ao máximo: o poder de combinação da sintaxe; a força evocativa da metáfora e a carga emocional das nossas atitudes, tanto as pensadas quanto as impensadas. (PINKER, 2005 apud BURGOS, 2018, online)

Por exemplo, ao tropeçar numa pedra, o falante pode emitir um 'palavrão' ou xingamento. Se dependesse do pensamento consciente, ninguém ofenderia uma coisa inanimada, mas a emissão do 'palavrão' expressa a raiva, a revolta e a dor do indivíduo naquele momento específico.

Embora comumente não sejam objeto de pesquisa, os 'palavrões' são altamente frequentes na fala dos seres humanos e há mais mistérios em seu universo do que o senso comum imagina (BURGOS, 2018).

Segundo Burgos (2018),

Enquanto a linguagem comum e o pensamento consciente ficam a cargo da parte mais sofisticada da massa cinzenta, o neocórtex, os palavrões "moram" nos porões da cabeça. Mais exatamente no sistema límbico. É o fundo do cérebro, a parte que controla nossas emoções. Trata-se de uma zona primitiva: se o neocórtex é mais avantajado que o dos outros mamíferos, o sistema límbico é bem parecido. Nossa parte animal fica lá. E sai, de vez em quando, na forma de palavrões. (BURGOS, 2018, online)

Assim, por exemplo, se um jogador de futebol grita o 'palavrão' porra ou caralho ao marcar um gol, não o faz por ser mal-educado, mas porque só uma 
palavra ou expressão saída diretamente do sistema límbico é capaz de expressar o que está sentindo naquele momento.

Quanto à avaliação social do 'palavrão', diz Jay (1999 apud BURGOS, 2018) que "perceber o xingamento como agressão ou ferramenta social depende do contexto".

Pinker (2005) considera o 'palavrão' até mais sofisticado do que a linguagem comum, pois transmite a emoção do sistema límbico de quem fala direto para o de quem ouve. Burgos (2018) diz ainda que os 'palavrões' saem como se fossem tiques nervosos sob a forma de palavras. E acrescenta que, como os 'palavrões' nascem na parte primitiva do cérebro, quase todos versam sobre duas coisas básicas da existência: 'sexo' e 'excrementos'. Aqui, servem como exemplos palavras como boceta, bunda, caralho, cu, culhões, foda, foder, pau, porra, rola - ligadas a 'sexo' - e cagar, cocô, merda, mijão - ligadas a 'excrementos'.

Então, se é fácil entender por que excrescências são 'palavrões', já que são coisas repugnantes, só se pode dizer o mesmo sobre os termos e expressões ligados ao 'sexo' se se considera que este traz riscos de doenças, exploração, pedofilia e estupro, males que "deixaram marcas nos nossos costumes e emoções" (PINKER, 2005 apud BURGOS, 2018). Isso ratifica o vetor social, cultural e histórico de que se revestem os 'palavrões'.

No que tange ao vetor religioso, os xingamentos vá para o inferno ou Satanás, por exemplo, podem ser bem impactantes se se considera que não há prognóstico pior do que não ir para o céu quando morrer. Em algumas comunidades e em algumas situações, essas expressões podem já não ser tanto "pesadas", tendo em vista que, segundo Pinker (2005 apud BURGOS, 2018), "a perda da eficácia das palavras tabus relacionadas à religião é uma óbvia consequência da secularização da cultura ocidental".

Muitas vezes, o 'palavrão' é resultado de uma palavra ou expressão que vira tabu, ou seja, ganha um sentido simbólico em algum momento histórico da língua. Diz Burgos (2018) que

Em algum momento da história do português, um sujeito chamou pênis de "pau". E uma palavra originalmente "pura" enveredava para o mau caminho. Nada mais comum: hoje ninguém se lembra mais de "caralho" como sendo a cestinha que ficava no alto do mastro dos navios, ou "boceta" como uma caixa pequena e redonda. (BURGOS, 2018, online)

Enfim, decidir se um termo ou expressão é ou não um 'palavrão' depende "dos mecanismos de conservação da língua, que são o ensino, os 
meios de comunicação e os dicionários" (BURGOS, 2018, online), do contexto sócio-histórico-cultural, da situação comunicativa do discurso e, sobretudo, da intenção do falante ao produzi-los e da interpretação do interlocutor ao ouvilos. A depender da situação, o mesmo 'palavrão' pode ser negativo ou positivo: Vá para a porra! (negativo); Você fez um trabalho da porra! (positivo).

\section{OS FILMES}

O filme Cidade Baixa, de 2005, foi dirigido por Sérgio Machado e traz como elenco principal os atores baianos Lázaro Ramos (no papel de Deco), Wagner Moura (no papel de Naldinho) e Alice Braga (no papel de Karinna).

A história retratada no filme - que põe em discussão os sentimentos de amizade, amor e ciúme - é a de dois amigos (Deco e Naldinho) que dividem um barco de carga a vapor em Salvador e dão carona a uma sensual prostituta (Karinna) com quem se relacionam. A atração física se transforma e ambos se apaixonam pela garota, o que abala os alicerces da amizade. Numa vida a três, eles buscam, nesse romance e na capital baiana, um novo rumo para as suas vidas. A censura do filme, com 100 minutos de duração e enquadrado no gênero drama, é de 18 anos.

O filme Ó Paí, Ó, de 2007, com base em peça homônima de Márcio Meirelles, foi dirigido por Monique Gardenberg e produzido por Augusto Casé, Paula Lavigne e Sara Silveira. Em seu elenco, conta com Lázaro Ramos (no papel de Roque), Dira Paes (no papel de Psilene), Wagner Moura (no papel de Boca) e Stênio Garcia (no papel de Sr. Jerônimo), além de muitos outros atores.

A história retratada no filme é a vida de moradores de um cortiço no Centro Histórico do Pelourinho, em Salvador, que compartilham a paixão pelo carnaval e a antipatia pela síndica do prédio (D. Joana). Entre a falta de dinheiro e o desejo de se divertir, tipos curiosos sobrevivem à custa de muita criatividade, ironia, sensualidade e música, buscando um lugar durante o carnaval, seja trabalhando seja brincando. A censura do filme, com 98 minutos de duração e enquadrado no gênero comédia musical, é de 14 anos.

A escolha desses dois filmes deveu-se às seguintes razões: a) as histórias de ambos se passam na cidade de Salvador; b) os atores dos filmes (com exceção de Stênio Garcia e Dira Paes - do filme Ó Paí, Ó) são baianos, portanto falantes nativos da variedade linguística estudada; c) todas as personagens principais são pessoas provenientes de classe social baixa, falantes, pois, da 
norma popular; d) ambos os filmes têm cenas de brigas e discussões, situações que propiciam o uso de 'palavrões'.

\section{METODOLOGIA}

Para a coleta dos dados, procedeu-se à assistência dos filmes, inclusive com legenda. Consideradas as situações de brigas, insultos, ofensas, em que as personagens intencionalmente querem agredir outras verbalmente, foram levantadas todas as ocorrências dos chamados 'palavrões'.

Os dados foram então codificados de acordo com as seguintes variáveis controladas na pesquisa: a) classe da palavra (substantivo, adjetivo, verbo, interjeição); b) função sintático-discursiva (sujeito, predicativo, vocativo, núcleo do sintagma verbal, complemento verbal, adjunto adnominal, adjunto adverbial); c) sexo (homem, mulher); d) faixa etária (até 40 anos, a partir de 50 anos); e) personagem (controle de cada falante); f) lexia (controle de cada 'palavrão'; g) filme (Cidade Baixa, Ó Paí, Ó).

A seguir, os dados foram processados pelo Programa GoldVarb $X$ (SANKOFF; TAGLIAMONTE; SMITH, 2005), ferramenta computacional utilizada em análises variacionistas, para cálculo das frequências das ocorrências em sua distribuição pelos fatores considerados. Como não se trata aqui de uma análise na perspectiva sociolinguística estrita, em que se buscam indícios de mudança linguística e seus condicionamentos, não foram gerados os pesos relativos. As variantes (os 'palavrões') não foram, pois, consideradas em situação de concorrência. A partir dos resultados quantitativos encontrados passou-se à análise qualitativa dos dados, exposta na seção seguinte.

Ressalte-se que a interpretação dos chamados 'palavrões' teve por base a intuição de falante nativa da pesquisadora, considerado o contexto em que se deu a interação apresentada nos filmes analisados.

\section{ANÁLISE DOS DADOS}

Considerados os dois filmes, foram encontradas 244 ocorrências de 'palavrões', 132 no filme Cidade Baixa e 111 no filme Ó Paí, Ó, distribuição considerada estatisticamente equilibrada entre as duas películas.

Documentou-se a existência de 61 lexias, dispostas em ordem alfabética (com o total de ocorrências) no Quadro 1, a seguir: 
Quadro 1: Lista de 'palavrões'

\begin{tabular}{|l|l|l|l|l|}
\hline Abestalhada (1) & Cocô (1) & Foder (1) & Miserável (5) & Rabão (2) \\
\hline Aborteira (1) & Comer (1) & Fodido(a)(s) (5) & Miséria (3) & Rabo (2) \\
\hline Alienado (1) & Corno (1) & Graxeira (1) & Mulambo (1) & Rola (1) \\
\hline Bicha (1) & Culhões (2) & Ignorante (1) & Negrinha (2) & Satanás (1) \\
\hline Boceta (2) & Descaradão (1) & Jegue (1) & Negro (12) & Tcheca (1) \\
\hline Bocetão (2) & Desgraça (4) & Lapa de boca (1) & Passada (1) & $\begin{array}{l}\text { Tomar no (meio } \\
\text { do seu) cu (5) }\end{array}$ \\
\hline Brocha (1) & $\begin{array}{l}\text { Desgraçado(a) } \\
(2)\end{array}$ & Lapa de rola (1) & Pau (2) & Veado (9) \\
\hline Bunda (1) & Droga (1) & Macumbeira (1) & Piriguete (3) & Xucro (1) \\
\hline Caceta (2) & Embocetado (1) & $\begin{array}{l}\text { Marmita } \\
\text { requentada (1) }\end{array}$ & Pivete (2) & Zorra (1) \\
\hline Cagar (3) & $\begin{array}{l}\text { Esculhambação } \\
(2)\end{array}$ & Matraca (1) & Peste (4) & \\
\hline Cambada (1) & Estrupício (1) & Merda (6) & Porra (103) & \\
\hline Cão (2) & $\begin{array}{l}\text { Filho da (de } \\
\text { uma) puta (4) }\end{array}$ & Mija (1) & $\begin{array}{l}\text { Puta que (o) } \\
\text { pariu (2) }\end{array}$ & \\
\hline Caralho (15) & Foda (1) & Mijão (1) & Putaria (4) & \\
\hline
\end{tabular}

Como se pode ver no Quadro 1, o 'palavrão' mais utilizado é porra, com 103 ocorrências, o que equivale a $42 \%$ do total de dados! O segundo mais frequente é caralho, com 15 ocorrências (6\% dos dados). O terceiro mais frequente é negro, com 12 ocorrências (4,9\% dos dados). Em quarto lugar, aparece veado, com 9 ocorrências (3,7\% dos dados). A seguir, vêm merda, com 6 ocorrências (2,5\% dos dados), fodido(a)(s), miserável e tomar no (meio do seu) cu, com 5 ocorrências ( $2 \%$ dos dados) cada. Com 4 ocorrências cada (1,6\% dos dados) aparecem desgraça, filho da (de uma) puta, peste e putaria. Cagar, miséria e piriguete ocorrem 3 vezes cada (1,2\% dos dados). Com 2 ocorrências cada $(0,9 \%$ dos dados) aparecem 13 'palavrões': boceta, bocetão, caceta, cão, culhões, desgraçado(a), esculhambação, negrinha, pau, pivete, puta que (o) pariu, rabão e rabo. Os demais 33 'palavrões' (abestalhada, aborteira, alienado, bicha, brocha, bunda, cambada, cocô, comer, corno, descaradão, droga, embocetado, estrupício, foda, foder, graxeira, ignorante, jegue, lapa de boca, lapa de rola, macumbeira, marmita requentada, matraca, mija, mijão, mulambo, passada, rola, satanás, tcheca, xucro, zorra) ocorrem apenas uma vez $(0,4 \%$ dos dados) no corpus analisado.

A Tabela 1, a seguir, ilustra a distribuição dos 'palavrões' que ocorreram no corpus: 
Tabela 1: Distribuição dos dados

\begin{tabular}{|c|c|c|}
\hline 'Palavrão' & Ocorrências & Percentual \\
\hline Porra & 103 & $42 \%$ \\
\hline Caralho & 15 & $6 \%$ \\
\hline Negro & 12 & $4,9 \%$ \\
\hline Veado & 9 & $3,7 \%$ \\
\hline Merda & 6 & $2,5 \%$ \\
\hline $\begin{array}{l}\text { Tomar no (meio do seu) cu, fodido }(a)(s) \text {, } \\
\text { miserável }\end{array}$ & $5 \times 3=15$ & $2 \% \times 3=6 \%$ \\
\hline $\begin{array}{l}\text { Desgraça, filho da (de uma) puta, peste, } \\
\text { putaria }\end{array}$ & $4 \times 4=16$ & $1,6 \% \times 4=6,4 \%$ \\
\hline Cagar, miséria, piriguete & $3 \times 3=9$ & $1,2 \% \times 3=3,6 \%$ \\
\hline $\begin{array}{l}\text { Boceta, bocetão, caceta, cão, culhões, } \\
\text { desgraçado(a), esculhambação, negrinha, pau, } \\
\text { pivete, puta que (o) pariu, rabão, rabo }\end{array}$ & $2 \times 13=26$ & $0,9 \% \times 13=11,7 \%$ \\
\hline $\begin{array}{l}\text { Abestalhada, aborteira, alienado, bicha, } \\
\text { brocha, bunda, cambada, cocô, comer, corno, } \\
\text { descaradão, droga, embocetado, estrupicio, } \\
\text { foda, foder, graxeira, ignorante, jegue, lapa de } \\
\text { boca, lapa de rola, macumbeira, marmita } \\
\text { requentada, matraca, mija, mijão, mulambo, } \\
\text { passada, rola, satanás, tcheca, xucro, zorra }\end{array}$ & $1 \times 33=33$ & $0,4 \% \times 33=13,2 \%$ \\
\hline Total & 244 & $100 \%$ \\
\hline
\end{tabular}

Merece destaque o altíssimo índice do 'palavrão' porra, que ocorreu 103 vezes, totalizando $42 \%$ dos dados. O Dicionário Houaiss da Língua Portuguesa assim registra o verbete:

porra /ô/ s.f. (1209 cf. Leges) 1 ant. Clava com ponta redonda e reforço de ferro 2 pedaço de pau; porrete, cacete $3 \mathrm{tab}$. o pênis $4 \mathrm{tab}$. m.q. ESPERMA 5 infrm. algo muito ruim; porcaria, merda <vou jogar fora esta $p$. deste telefone celular> interj. 6 expressão de surpresa, espanto $<p$. ! que carvão você comprou! $>7$ expressa uma situação de dor ou aborrecimento <p.! quem deixou essa pedra no caminho?> uso no Brasil, esta palavra tabuística é mais típica da linguagem masculina informal e usase: 1) no final de uma frase como recurso enfático, para dar mais força ao enunciado (p.ex.: Faz o que eu disse, p.!); 2) como marcador frasal, colocado no final de certas unidades, como orações, frases, períodos, sem finalidade de ênfase ETIM prov. de porro, vegetal de talo longo e um bulbo num dos extremos, sugerindo a comparação com um bastão de cabo grosso; Corominas comenta que um lat. 
*porrěa, de caráter adj., '(maça) semelhante a um porro (alho)', der. do lat. pŏrrum ou porrus, $i$ 'porro (alho)' poderia explicar o voc. port.; ver porr- SIN/VAR pô, poça, poxa; ver tb. sinonímia de esperma. (HOUAISS, 2001, p. 2265)

Com exceção da primeira acepção, todas as outras foram encontradas no corpus. E a descrição do verbete atende plenamente aos sentidos e usos dessa palavra no falar baiano. O produtivo uso de porra no falar baiano já foi inclusive objeto de investigação de Santana, Jesus e Oliveira (inédito), em artigo intitulado "Estudo sobre a gramaticalização de porra no dialeto baiano: 'Que porra é essa?"', que discutem a natureza da modificação semântica, sintática e discursivo-pragmática nas diversas realizações da forma porra, seguindo a proposta da Gramaticalização, a partir de dados sincrônicos do português escrito e falado na Bahia. Os autores concluem que o item porra está passando por um processo de gramaticalização, saindo da categoria lexical de nome em direção a categorias gramaticais, comportando-se como advérbio, interjeição, conjunção e até mesmo como marcador discursivo. E propõem uma escala de gramaticalização para os dez diferentes usos de porra que encontraram:

Por meio dos dez tipos de porra verificados na análise, vimos que a transição tem como intermédio a ambiguidade semântica, a qual representa o "elo perdido" da recategorização. Podemos afirmar também que o item porra passou por processos diversos de semantização, sintaticização, discursivização, paradigmatização e erosão fonética, os quais promoveram um deslizamento do sentido em direção do mais concreto para o mais abstrato: alho porro $>$ pau/bastão/cacete/clava $>$ pênis $>$ sêmen/esperma $>$ nome [coisa] $>$ adjetivo $>$ advérbio $>$ conjunção $>$ exclamação/interjeição > marcador discursivo. (SANTANA; JESUS; OLIVEIRA, inédito, p. 18)

Nota-se, então, que são necessários mais estudos sobre o tema, pois muitos 'palavrões' são expressões gramaticalizadas ou em processo de gramaticalização. São usos criativos e extremamente contextualizados de lexias que deslizam de seu sentido original e ganham novo significado no ato discursivo, podendo, inclusive, sofrer recategorização.

Dos 244 dados encontrados nos filmes sob análise, 197 'palavrões' são substantivos, o que equivale a 80,7\% dos dados. Os adjetivos aparecem em 31 ocorrências, o que equivale a $12,7 \%$ dos dados. As interjeições ocorrem 10 vezes ( $4,1 \%$ dos dados) e os verbos ocorrem apenas em 6 dados (2,5\% dos dados). Os exemplos de (1) a (4) ilustram, respectivamente, cada uma dessas classes gramaticais: 
(1) Estrupício! Peste! Sai! [Maria falando com Yolanda, Ó Pái, Ó]

(2) Miserável! Miserável, rapaz! [Boca falando com Roque, Ó Paí, Ó]

(3) Ai! Que porra! [Yolanda, ao cair, Ó Paí, Ó]

(4) Vá se foder na casa da desgraça, seu filho de uma puta! [Deco, Cidade Baixa]

O fato de os substantivos predominarem explica-se por ser esta a classe mais abundante nas línguas e, portanto, as mais susceptíveis a metaforizações e a extensões de significado para nomearem as coisas, os seres, os sentimentos do mundo. Estando muitos 'palavrões' associados aos campos léxico-semânticos de 'sexo' e 'excremetnos', segundo Burgos (2018), são os substantivos que se prestam a externar isso. Os nomes (substantivos e adjetivos) constituem uma série aberta e bastante polissêmica, o que lhes confere um caráter de maleabilidade na busca por expressividade e subjetividade linguísticas.

Quanto à função sintático-discursiva, os dados se distribuem conforme a Tabela 2, a seguir:

\begin{tabular}{l|c|c}
\hline Função sintático-discursiva & Ocorrências & Percentual \\
\hline Complemento verbal & 74 & $30,3 \%$ \\
\hline Vocativo & 56 & $23 \%$ \\
\hline Adjunto adverbial & 38 & $15,6 \%$ \\
\hline Predicativo & 30 & $12,3 \%$ \\
\hline Sujeito & 21 & $8,6 \%$ \\
\hline Adjunto adnominal & 20 & $8,2 \%$ \\
\hline Núcleo do SV & 5 & $2 \%$ \\
\hline Total & 244 & $100 \%$ \\
\hline
\end{tabular}

As funções sintático-discursivas controladas estão exemplificadas de (5) a (11), a seguir, na mesma ordem da Tabela 2:

(5) Leva esse veado daqui! [Neuzão, falando com Roque, Ó Paí, Ó]

(6) O que é, lapa de boca? [Carmem, falando com Lúcia, Ó Paí, Ó]

(7) O galo mija pra caralho! ${ }^{3}$ [Naldinho, Cidade Baixa]

\footnotetext{
${ }^{3}$ Frase interpretada como "O galo mija muito!".
} 
(8) Você é negro! Você é negro! Você é negro! Você é negro! Você é negro! ${ }^{4}$ [Boca falando com Roque, Ó Paí, Ó]

(9) Foi um acidente essa porra! [Naldinho, Cidade Baixa]

(10) Agora eu vou ser o Papai Noel dos brocha! [Naldinho, Cidade Baixa]

(11) Você comeu a menina, brother? [Naldinho, Cidade Baixa]

Esperava-se que os 'palavrões' ocorressem mais com as funções de vocativo, predicativo e sujeito por serem estas predominantes em frases declarativas com a intenção de xingar, insultar ou ofender alguém. No caso dos filmes analisados, o expressivo uso de 'palavrões' na função de complemento verbal (objeto direto e indireto) deve-se ao fato de o xingamento, insulto ou ofensa serem indiretos. Ou seja, em vez de se dirigir diretamente ao alvo, o falante dirige-se a outra pessoa também presente na cena referindo-se ao alvo de forma agressiva, como atesta o exemplo (5). Quanto à função de adjunto adverbial, esta supera as de predicativo e sujeito devido à alta ocorrência de válvai pra porra, como se pode ver no exemplo (12):

(12) Se pique daqui, vá pra porra! [Neuzão, falando com Matias, Ó Paí, Ó]

Em relação à variável 'sexo', os dados mostram que os 'palavrões' são bem mais frequentes na fala dos homens (190 dados - 77,9\%) do que na fala das mulheres (54 dados - 22,1\%). Observe-se a distribuição dos dados por sexo no Gráfico 1, a seguir:

4 Nessa frase, que se repete, vê-se claramente no filme a intenção de Boca de ofender Roque, não só pelo contexto em que produz o enunciado mas também pelo crescente tom de voz e pela expressão facial. 


\section{Gráfico 1: Uso de 'palavrões' e sexo do falante}

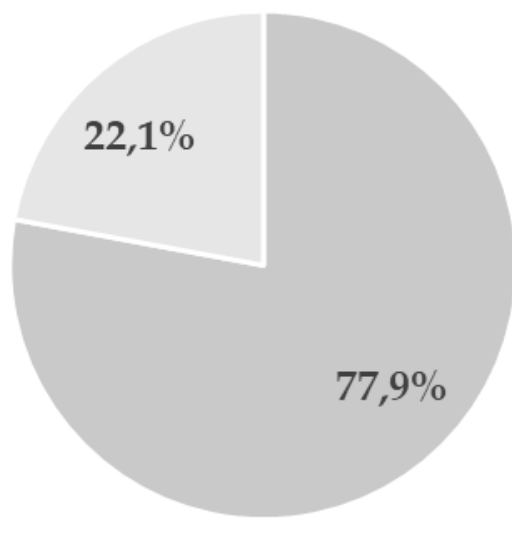

Homens Mulheres

Na sociedade baiana e brasileira, em geral, os homens têm mais liberdade linguística quanto ao uso de 'palavrões' e de linguagem de 'baixo calão'. As mulheres, ao contrário, tendem a ter um comportamento linguístico menos marcado no que tange a estigmas sociais. Não é à toa que comentários como "isso não cai bem na boca de uma mulher" ou "mulher não pode ter uma boca porca" são comumente ouvidos na comunidade soteropolitana, sobretudo quando as mães desempenham o papel de educar as filhas.

No caso dos filmes analisados, são os homens, de forma geral, que exercem mais poder social (em termos de trabalho, de sustento familiar, de imposição de respeito) do que as mulheres nas comunidades da Cidade Baixa e do Pelourinho, resquícios de uma sociedade ainda machista. Como ilustração, seguem exemplos, respectivamente, da fala de um homem e de uma mulher encontrados na amostra:

(13) Vá tomar no meio do seu cu, meu irmão! [Naldinho, Cidade Baixa]

(14) Vão acabar fazendo merda! [Karinna, Cidade Baixa]

Quanto à faixa etária, a análise dos dados permite constatar que os 'palavrões' são mais frequentes na fala dos mais jovens (212 dados - 86,9\%) do que na fala dos mais velhos (32 dados - 13,1\%), muito embora a distribuição das ocorrências tenha sido desequilibrada pelo próprio desequilíbrio da amostra, já que em ambos os filmes há mais personagens que aparentam ter até 40 anos do que personagens que parecem ter mais de 50 anos. Foram registrados 212 dados 
em falantes considerados jovens e apenas 32 dados em falantes acima dos 50 anos. O Gráfico 2, abaixo, ilustra os resultados encontrados:

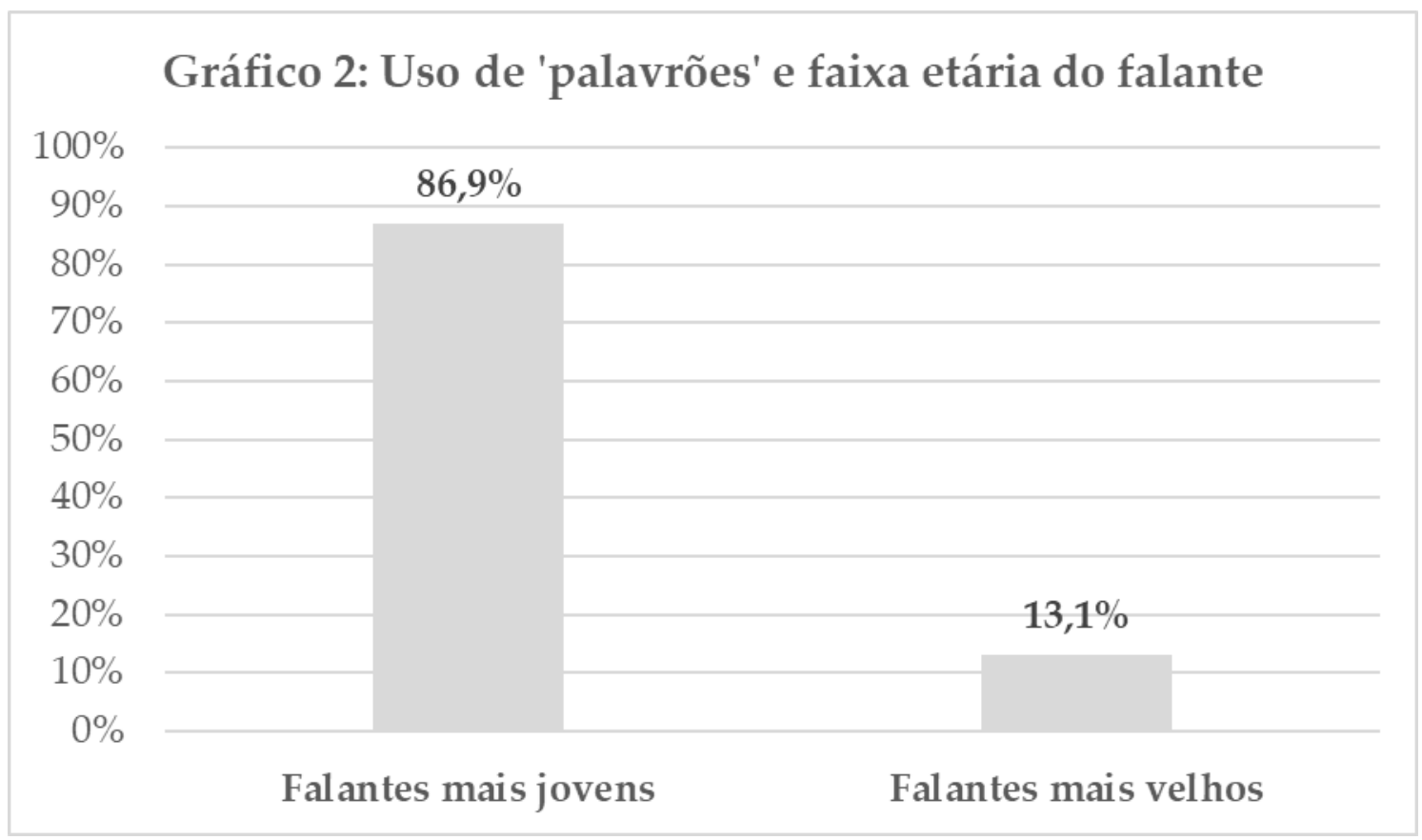

Apesar de a amostra não apresentar equilíbrio em relação à quantidade de falantes mais jovens e mais velhos, os resultados permitem aventar a hipótese de que os 'palavrões' são mais usados entre os mais jovens, pois estes, em geral, têm maior liberdade de expressão e menos comprometimento com as normas sociais, visto que não são modelos de comportamento como o são os mais velhos, que devem "dar o exemplo" aos filhos no que concerne às chamadas "normas de conduta social".

Os exemplos (15) e (16) ilustram a fala de uma personagem mais jovem e de uma personagem mais velha, respectivamente:

(15) Puta que o pariu! [Naldinho, Cidade Baixa]

(16) Não tá vendo que eu tô comendo, porra? [amigo de Naldinho, Cidade Baixa]

No que concerne à distribuição dos dados por personagem, observou-se que as ocorrências se concentram em três personagens, duas do filme Cidade Baixa (Naldinho - 73 dados, Deco - 43 dados) e uma do filme Ó Paí, Ó (Boca 30 dados). Em quarto lugar aparece a personagem Roque, com 16 dados, também do filme Ó Paí, Ó. Essas quatro personagens são exatamente as personagens principais dos dois filmes analisados. 
Considerando a hipótese de Burgos (2018), de que a maioria dos 'palavrões' está associada a 'sexo' e 'excrementos', procedeu-se à categorização dos dados encontrados nesta pesquisa por essas duas áreas semânticas, exposta no Quadro 2, a seguir:

Quadro 2: Distribuição dos 'palavrões' por área semântica

\begin{tabular}{|l|l|}
\hline \multicolumn{1}{|c|}{ Área semântica } & \multicolumn{1}{|c|}{ 'Palavrões' do corpus } \\
\hline 'Sexo' & $\begin{array}{l}\text { bicha, boceta, bocetão, brocha, bunda, caceta, caralho, comer, } \\
\text { corno, culhões, descaradão, embocetado, filho da (de uma) puta, } \\
\text { foda, foder, fodido(a)(s), lapa de rola, marmita requentada, } \\
\text { passada, pau, piriguete, porra, puta que (o) pariu, putaria, } \\
\text { rabão, rabo, rola, tcheca, tomar no (meio do seu) cu, veado }\end{array}$ \\
\hline 'Excrementos' & cagar, cocô, merda, mija, mijão \\
\hline
\end{tabular}

Foram aqui consideradas também ligadas a 'sexo' as lexias bicha, comer, corno, descaradão, marmita requentada, passada, piriguete e veado devido ao sentido que assumem nos enunciados documentados nos filmes. No caso de bicha e veado, ambas têm a ver com a opção sexual do insultado. No caso de comer, foi usado no sentido de 'ter relações sexuais'. Corno refere-se ao 'homem que é traído pela mulher, que tem (ou teve) relações sexuais com outro'. Descaradão aparece no corpus como 'homem que mantém relações sexuais com muitas mulheres'. As lexias marmita requentada e passada referem-se a 'mulher que já teve relações sexuais com muitos homens'. E piriguete é um termo usado para se referir à 'mulher que se insinua para o homem com o objetivo de ter relações sexuais com ele'.

Percebe-se que, de longe, os 'palavrões' ligados a 'sexo' são bastante numerosos, muitos deles recorrentes, no corpus. Considerando a relação entre língua e sociedade, pode-se associar essa protuberância de 'palavrões' originados desse campo léxico-semântico à sexualidade baiana, expressa, por exemplo, nas letras de músicas, nas danças, no vestuário.

Além disso, tanto 'sexo' quanto 'excrementos' são temas considerados tabu nas sociedades em geral, motivo pelo qual possibilitam a metaforização de muitas expressões a eles associadas que se tornam 'palavrões', uma forma de externar, em situações de subjetividade extrema - algumas vezes de forma impensada -, aquilo que socialmente não é bem aceito e deve ser evitado em situações normais. 
Cumpre ainda comentar alguns 'palavrões' que fogem ao escopo do 'sexo' e dos 'excrementos' e que foram documentados nesta pesquisa.

As lexias miserável, miséria e peste referem-se a fatos sociais e/ou históricos que ainda permanecem no imaginário popular como coisas negativas. Os termos miserável e miséria denotam pobreza extrema e peste foi uma doença que assolou grande parte da população mundial no passado, portanto algo que ninguém deseja nem para si nem para outrem, a não ser nos casos de insulto, repulsa, raiva.

As lexias cão, desgraça, desgraçado, macumbeira e satanás remetem ao campo religioso. Cão e satanás representam o demônio, o oposto de Deus, o que traz o mal, de acordo com as crenças cristãs. São, portanto, palavras que se prestam a ofender qualquer pessoa que integre uma sociedade carregada de religiosidade, como é o caso da Bahia. As palavras desgraça e desgraçado, por sua vez, etimologicamente, relacionam-se à 'falta de graça'. E graça, aqui, também é de cunho religioso, pois falta a 'graça de Deus'. Já macumbeira é um termo relacionado, pejorativamente, ao Candomblé, religião de origem africana trazida pelos escravos. Daí tornar-se ofensa numa sociedade cuja religião predominante é a cristã e na qual ainda há muito preconceito em relação às práticas religiosas afrodescendentes.

As lexias abestalhado e jegue remetem a animais utilizados em trabalhos pesados, para carregar cargas. Uma pessoa assim chamada é, pois, rebaixada à condição de animal explorado, havendo aí também a conotação de lento e/ou pouco inteligente. $\mathrm{O}$ termo ignorante também é usado como xingamento para denotar não alguém que desconhece algo mas aquele que é desprovido de educação, que é estúpido, com uma carga, portanto, bastante negativa. Já alienado, no corpus desta pesquisa, foi usado como 'palavrão' para ofender um pai de aluno que não concordava com o abaixo-assinado divulgado pela professora de seu filho. Claramente, no filme, a professora o xinga com o mesmo sentido do 'palavrão' ignorante, já descrito.

Os 'palavrões' negrinha e negro estão diretamente ligados à questão racial. Numa sociedade, como é o caso da Bahia, com uma grande parcela da população afrodescendente, tais termos remetem ao passado escravocrata, quando ser negro significava ser escravo e, portanto, inferior. O termo graxeira também se enquadra nessa categoria, visto que assim era chamada a escrava que trabalhava na casa dos brancos. Assim, facilmente, essas lexias são imbuídas de sentido negativo e utilizadas para agredir, ofender, humilhar. 
Já o termo droga, ao ser utilizado como 'palavrão', retoma seu sentido original de medicação, mas acrescido de sentido pejorativo associado a 'narcótico', algo que deve ser reprimido e evitado. Claro que, em muitos contextos em que a palavra é utilizada, esse sentido pejorativo já se perdeu, como, por exemplo, quando alguém tropeça e a enuncia como uma interjeição. Aborteira, também associado à área médica, é um termo usado para denotar a pessoa que realiza aborto, prática considerada ilegal. No caso do corpus analisado, a palavra foi usada para expor e humilhar uma personagem que costuma praticar abortos em casa. Note-se que aí também há um quê religioso, já que a fé cristã condena veementemente o aborto, tema também tabu em muitas sociedades.

O item cambada refere-se a um conjunto de pessoas que praticam o mal, que praticam crimes, sentido que remete a uma de suas acepções dicionarizadas. Torna-se 'palavrão' quando usado de forma a denotar pessoas indesejadas. E pivete refere-se a menino que furta, que rouba, que vive nas ruas, 'palavrão' usado também para se dirigir a criança indesejada. Estrupício apareceu no corpus em referência a um catador de latinha que, sem abrigo, morava no corredor do cortiço e, portanto, era alguém também indesejado, que incomodava e causava medo em alguns moradores.

Esculhambação e zorra são 'palavrões', quando revestidos de carga emotiva, para designar situações de bagunça, de briga, denotando que algo está errado, fora de ordem.

Já as expressões lapa de boca e matraca foram usadas como 'palavrões' dirigidos a pessoas que costumam falar mal de outras, que fazem 'fofoca', ou que dizem coisas que o interlocutor não deseja ouvir.

Finalmente, mulambo refere-se a uma pessoa de aparência feia, que não se cuida, alguém desarrumado ou mal arrumado. E xucro refere-se a pessoa tola, ignorante, que desconhece ou sabe muito pouco sobre determinado assunto.

Enfim, o que se pode observar é que os 'palavrões' documentados no corpus preservam, em sua grande maioria, sentidos ou acepções registrados em dicionários, em muitos casos acompanhados também do registro de 'uso popular' ou de 'calão' ou de 'gíria' ou de 'linguagem chula'. E são usados de forma 'negativa' exatamente para expressar o sentimento de raiva, repulsa, ódio, indignação, dor, medo, seja em relação a alguém, seja em relação a determinada situação. 


\section{CONSIDERAÇÕES FINAIS}

Nesta pesquisa sobre os 'palavrões' no português baiano a partir de uma análise sociolinguística com base nos filmes Cidade Baixa e Ó Paí, Ó, cujas histórias se passam em Salvador, foram coletados 244 dados, sendo 132 no filme Cidade Baixa e 111 no filme Ó Paí, Ó.

Das 61 lexias documentadas, porra ocupou o primeiro lugar em frequência, com 103 ocorrências, o que equivale a 42\% dos dados. Atesta-se, pois, que porra é, de fato, o 'palavrão' mais utilizado pelos baianos.

Considerando a classe gramatical dos 'palavrões', os substantivos predominaram, com 197 ocorrências, o que corresponde a 80,7\% dos dados.

No que diz respeito à função sintático-discursiva, os complementos verbais foram os mais produtivos, com 74 ocorrências, ou seja, 30,3\% dos dados, ficando o vocativo em segundo lugar, com 56 ocorrências, ou seja, $23 \%$ dos dados.

Quanto às variáveis extralinguísticas, os 'palavrões' foram mais utilizados pelos homens (190 dados - 77,9\%) e pelos mais jovens (212 dados $86,9 \%)$, em comparação com as mulheres e com os mais velhos.

A partir do controle das personagens, verificou-se que os 'palavrões' são mais frequentes exatamente nas personagens principais de ambos os filmes: em Cidade Baixa, Naldinho produziu 73 dados e Deco produziu 43 dados; em Ó Paí, Ó, Boca produziu 30 dados e Roque produziu 16 dados.

Confirmando o que diz Burgos (2018) sobre o campo léxico-semântico dos 'palavrões', a grande maioria dos dados encontrados refere-se ou deriva das áreas 'sexo' e 'excrementos'.

Como exposto ao longo da análise dos dados encontrados no corpus da pesquisa, está clara mais uma vez a relação entre os usos linguísticos e a história, a sociedade e a cultura locais da comunidade de fala.

Cumpre ressaltar, à guisa de conclusão, que esta pesquisa, longe de ser exaustiva, tomou como objeto algo ainda muito pouco investigado e que merece continuidade. Além disso, ainda carecem de discussão a metodologia de coleta desse tipo de dado e os critérios não só de interpretação como também de categorização dos chamados 'palavrões', cuja definição perpassa, inevitavelmente, por considerações muito subjetivas. 
Abre-se então aqui um campo vasto para estudos. Se o tema despertar o interesse de outros investigadores, o diálogo está sempre aberto para as trocas, pois descrever a língua em uso - e em sua relação com a sócio-história e com a cultura dos que a falam - é um desafio infindável, sobretudo no que tange à expressão de subjetividade em situações de extrema carga emotiva, como é o caso dos 'palavrões'.

\section{REFERÊNCIAS}

AULETE, Caldas. Dicionário Caldas Aulete da língua portuguesa: edição de bolso. Rio de Janeiro: Lexicon, 2007.

BURGOS, Pedro. A ciência do palavrão. Super Interessante, 22 de janeiro de 2018. Disponível em: https://super.abril.com.br/ciencia/a-ciencia-do-palavrao/. Acesso em: 18 jun. 2018.

CIDADE BAIXA. Direção de Sérgio Machado. Filme da Coleção Isto É. Brasil: 2005. Manaus: Videolar S.A., 2005. [DVD]. (100 minutos), colorido.

FERREIRA, Aurélio Buarque de Holanda. Novo dicionário Aurélio da língua portuguesa. Rio de Janeiro: Nova Fronteira, 1986.

HOUAISS, Antônio. Dicionário Houaiss da língua portuguesa. Rio de Janeiro: Objetiva, 2001.

Ó PAÍ, Ó. Direção de Monique Gardenberg. Filme de Europa Filmes e Globo Filmes. Brasil: 2008. Manaus: Videolar S.A., 2007. [DVD]. (98 minutos), colorido.

PINKER, Steven. The stuff of thought. Londres: Penguin Group, 2005.

SANKOFF, D.; TAGLIAMONTE, S.; SMITH, E. GoldVarb X - a multivariate analysis application. Toronto: Department of Linguistics; Ottawa: Department of Mathematics, 2005.

SANTANA, Jan Carlos Dias; JESUS, Luziane Amaral; OLIVEIRA, Josane Moreira. Estudo sobre a gramaticalização de porra no dialeto baiano: 'Que porra é essa?'. Trabalho inédito.

WIKIPÉDIA. A enciclopédia livre. Disponível em: https://pt.wikipedia.org/wiki/Palavra_de_baixo_cal\%C3\%A3o. Acesso em: 18 jun. 2018.

Nota do editor:

Artigo submetido para avaliação em: 12 de agosto de 2018.

Aprovado em sistema duplo cego em: 19 de setembro de 2018. 